\title{
The Influence of Environmental Regulation on the Efficiency of China's Regional Green Economy Based on the GMM Model
}

\author{
Rong Wang* \\ Nanjing Institute of Technology, Jiangning Science Park, Nanjing, China
}

Received: 22 May 2019

Accepted: 24 July 2019

\begin{abstract}
Based on the panel data of 30 provinces in China from 2005 to 2017 and on the construction of the green economy efficiency measurement index system, this paper uses the super-efficient DEA model to measure national green economy efficiency considering undesired output. The system GMM model analyzes the impact of environmental regulation on the efficiency of the green economy. The results show that from the national sample, the relationship between environmental regulation and green economic efficiency has a "U" shape. When the environmental regulation intensity is kept within a certain "critical point", its impact on the efficiency of green economy has inhibition, but if this strength exceeds this "tipping point", its impact is promoted. From the sub-samples of the three regions, the environmental regulation of the central and western regions has an inhibitory effect on the efficiency of the green economy, the impact of environmental regulation on the eastern region is promoted, and the eastern characteristics are the same as the national empirical analysis. The remarkable " $U$ " relationship can be found to be more effective in improving the efficiency of the green economy in economically developed regions.
\end{abstract}

Keywords: super efficient DEA, environmental regulation, green economic efficiency

\section{Introduction}

In 2018, Xi Jinping's ecological civilization thought was formally established. The new development concept, ecological civilization, and beautiful China were enshrined in the China's constitution. For the first time, the National Environmental Protection Conference was held in the name of the Party Central Committee, and the call for a good fight against pollution was launched. The report also pointed out

*e-mail: wxr920@163.com that the construction of ecological civilization is the millennium of China's sustainable development, and the key point is to improve the quality of the ecological environment. It can be seen that green development has become an imperative development concept and development mode under the background of "new normal". The concept of green development is based on the idea of "sustainable development". It is a new development model with the core of correctly handling the relationship between economic development and environmental protection. Among them, the term "green economic efficiency," which has evolved from the concept of "green development" and has a strong 
representativeness, has become a hot topic of scholars [1-5]. The public product attributes of the environment and the negative externalities of environmental pollution make it difficult for market mechanisms to effectively solve environmental pollution problems. Environmental regulations are an important breakthrough to make up for market failures. Based on this, one question worth pondering is whether strict environmental regulation will lead to a decline in green economy efficiency that takes into account environmental pollution factors, or support the "Porter hypothesis", which can achieve economic growth while improving environmental quality [6-10]. In order to promote the efficiency of a green economy, the study of the relationship between environmental regulation and green economy efficiency has become the focus of academic circles.

With regard to the study of the impact of environmental regulation on the efficiency of green economy, many scholars have drawn different conclusions and can be roughly divided into three types. First, environmental regulation will promote the development of green economy efficiency to a certain extent. For example, environmental regulation can promote the "diffusion effect" and "polarization effect" of green economy efficiency through the screening effect, internal technology spillover and external technology spillover, which will promote the efficiency of green economy in the region and surrounding areas [11-13]. Second, environmental regulation has a negative impact on the efficiency of the green economy. For example, as the level of environmental regulation increases, companies will be forced to attach new target constraints to the original technical level. Thus, it has a negative impact on the speed, direction and scale of technological innovation, which in turn has a negative impact on the efficiency of the green economy [1415]. Third, the impact of environmental regulation on green economy efficiency is characterized by phase and nonlinearity. For example some studies find that environmental regulation has a "non-linear" and "time-lag" effect on green economy efficiency, and through empirical discovery, with the improvement of environmental regulation levels, green economy efficiency shows a "U" trend that rises first and then rises. Some studies have also found that with the improvement of environmental regulation levels, green economy efficiency shows a reverse " $U$ " relationship of promoting post-inhibition [16-18].

From the above research status and development dynamics analysis, we can find that the theoretical and empirical research on green economy efficiency and environmental regulation have achieved relatively fruitful results, but because the mechanism of environmental regulation is different and complex, on the one hand, the environment regulation may have potential inhibitory effects on economic efficiency, and on the other hand, it may "force" technology upgrades and improve economic efficiency. Therefore, different results may occur in different periods and different regions. It is necessary to study the differences between regions and provide theoretical references for proposing differentiation strategies [19-21]. Based on the above analysis, this paper combines the current stage characteristics of China's regional economic development, considers the "non-expected" output generated during the development process, and uses the super-efficient DEA model to calculate the green economy efficiency of various regions in China, and from the overall and sub-regions study between the regions. Furthermore, the system GMM model is used to analyze green economy efficiency and environmental regulation levels and other related influencing factors, focusing on the impact of China's environmental regulation level on green economy efficiency, and it is expected to provide a certain reference and basis for realizing green development.

\section{Materials and Methods}

\section{Measurement of China's Regional Green Economy Efficiency}

\section{Data Envelopment Analysis (DEA)}

The DEA method proposed in this paper is used for calculation, because it does not need to assume the specific functional form in advance, and the weight in the model is generated by mathematical programming, eliminating the artificial and subjective factors [9]. Therefore, this paper uses the DEA method to build an analysis model of China's regional green economy efficiency. The DEA model calls the "unit" or "department" to be evaluated as DMU, and each decision-making unit (area) has $m$ inputs (input) and $n$ outputs (output), which represent resources, consumption and output effectiveness. The $\mathrm{i}$ unit is denoted as $\mathrm{DMU}_{\mathrm{i}}$ $(\mathrm{i}=1,2, \ldots, \mathrm{N})$, and its input and output forms are:

$$
\begin{aligned}
& X_{i}=\left(x_{1 i}, x_{2 i}, \cdots, x_{m i}\right)^{T}>0 \\
& Y_{i}=\left(y_{1 i}, y_{2 i}, \cdots, y_{m i}\right)^{T}>0
\end{aligned}
$$

The corresponding weight vector is set to:

$$
\begin{aligned}
& \mathrm{U}=\left(\mu_{1}, \mu_{2}, \cdots, \mu_{m}\right)^{T} \geq 0 \\
& \mathrm{~V}=\left(v_{1}, v_{2}, \cdots, v_{n}\right)^{T} \geq 0
\end{aligned}
$$

The $\mathrm{DMU}_{\mathrm{i}}$ efficiency evaluation index is:

$$
h_{i}=\frac{V^{T} Y_{i}}{U^{T} X_{i}}=\frac{\sum v_{r} y_{r i}}{\sum \mu_{j} x_{j i}}(i=1,2,3, \cdots, N)
$$

Assume that the decision unit being evaluated is i0, and $\mathrm{DMU}_{\mathrm{i} 0}$ is recorded. Under the condition that the efficiency index of each decision unit does not exceed 
one, select the appropriate weight vector $\mathrm{U}$ and $\mathrm{V}$ to achieve $\frac{V^{T} Y_{i 0}}{U^{T} X_{i 0}}$ The maximum, that is, the optimization model of $\mathrm{DMU}_{\mathrm{i} 0}$ is:

$$
\left\{\begin{array}{l}
\mathrm{D}\left(X_{i 0}, Y_{i 0}\right)=\max \left(\frac{V^{T} Y_{i 0}}{U^{T} X_{i 0}}\right) \\
\text { s.t. } \frac{V^{T} Y_{i}}{U^{T} X_{i}} \leq 1 \\
\mathrm{U} \geq 0, \mathrm{~V} \geq 0,(i=1,2,3, \cdots, \mathrm{N})
\end{array}\right.
$$

For the traditional DEA model, if multiple decision units are at the same time leading to the production frontier and multiple decision units are simultaneously effective, the model will not be able to further evaluate and compare the merits of effective decision units. Anderson and Peterson (1993) established that an investment-oriented super-efficiency DEA model is used to make up for this deficiency, which can make the effective decision unit efficiency value greater than one. The super-efficient DEA (SE-DEA) model is as follows.

$$
\left\{\begin{array}{l}
D\left(X_{i 0}, Y_{i 0}\right)=\max \left(\frac{V^{T} Y_{i 0}}{U^{T} X_{i 0}}\right) \\
\text { s.t. } \frac{V^{T} Y_{i}}{U^{T} X_{i}} \leq 1 \\
U \geq 0, V \geq 0,(i=1,2,3, \cdots, N), i \neq i_{0}
\end{array}\right.
$$

The advantages of this method are as follows: first, objectivity, avoiding subjective consciousness; second, the DEA method does not need to be normalized; third, it can reflect the effectiveness of production activities; and fourth, it can provide auxiliary management for producers.

\section{Indicator Selection and Data Sources}

The green economic efficiency index to pursue the balance of social economic and ecological environment benefit, need through the use of inputs in the production operation efficiency, obtaining the expected output ability to make, and also to the production and operating activities of additional output obtaining the expected output at the expense of resources and environment to make considerations.

In this paper, the indicator system of input and output required for green economy efficiency is constructed (see Table 1). Because this cannot be directly obtained from the statistical yearbook of the provinces, autonomous regions and municipalities directly under the central government capital stock data, the author references Pittman and others through the use of the perpetual inventory method to measure capital stock. According to energy input, this paper will be a total energy consumption as energy input, using the method of linear interpolation fitting part year missing data. For the labor force, the number of people in each province who have participated in employment is extracted in order to estimate the labor force input in the model.

There are two kinds of output: expected output and unexpected output. Among them, expected output refers to regional GDP, which is used to measure the actual situation of the regional economy. Domestic ecological pollution is dominated by industrial pollution. As a national key monitoring object, its relevant data is relatively perfect. Industrial waste water, industrial waste gas and solid waste were selected as the non-expected output indexes [22]. Relevant data were collected from China's environmental statistics yearbook.

The study looked at annual data from 30 Chinese provinces, autonomous regions and municipalities from 2005 to 2017. Relevant data were collected from the China statistical yearbook, the China environmental yearbook, the China environmental statistical yearbook, the China environmental statistical yearbook, the China energy statistical yearbook, the China urban statistical yearbook, the China science and technology statistical yearbook and the provincial statistical yearbook. In consideration of the availability of data, studies on the Tibet autonomous region, Macao, Hong Kong, Taiwan and other places are excluded. In order to minimize the impact of price factors on the conclusion of the econometric analysis, the data are converted into comparable price indexes by using regional price indexes over the years.

Table 1. Green economy efficiency measurement index system.

\begin{tabular}{|c|c|c|}
\hline \multirow{3}{*}{ Index } & Index classification & Index composition \\
\hline \multirow{3}{*}{ Input index } & Labor & Employment population in each region \\
\cline { 2 - 3 } & Capital & Capital stock \\
\cline { 2 - 3 } & Energy & Total energy consumption \\
\hline \multirow{3}{*}{ Output indicators } & Expected output & GDP \\
\cline { 2 - 3 } & Non-expected output & Industrial wastewater discharge emissions \\
\cline { 2 - 3 } & & Industrial exhaust emissions \\
\cline { 2 - 3 } & & Industrial solid waste discharge emissions \\
\hline
\end{tabular}




\section{Result of Green Economy Efficiency}

By using DEAP 2.1 software, the determined input index and output index were substituted into the model, and the results are shown in Table 2 .

According to the above-mentioned points area, the overall efficiency of the green economy in Beijing, Shanghai, Tianjin, and Guangdong in a higher position, were higher than 0.9 , the green economic efficiency in the area under 0.5 to 10 , respectively, Guizhou, Gansu, Hebei, Liaoning, Shanxi, Shaanxi, Ningxia, Qinghai, Xinjiang and Qinghai. These areas are low green efficiency, and there are 6 regional distribution in the west, that most of these areas are green economic efficiency is low in the west. The areas between 0.5 and 0.9 accounted for the majority. It can be seen that green economic efficiency reflects certain heterogeneity in different regions, so it is necessary to further analyze the main factors affecting green economic efficiency.

\section{Environmental Regulations Impact on the Chinese Green Economy Efficiency}

\section{Variable Selection}

The explained variable of this paper is green economic efficiency (GF).

This paper mainly reveals that green economic efficiency is affected by environmental regulation (ER), so the author chooses ER as the core explanatory variable. ER is expressed by the proportion of the cost of treating industrial wastewater, industrial waste gas and

Table 2. Calculation results.

\begin{tabular}{|c|c|c|c|c|c|c|c|c|c|c|c|c|c|c|c|}
\hline & Region & 2005 & 2006 & 2007 & 2008 & 2009 & 2010 & 2011 & 2012 & 2013 & 2014 & 2015 & 2016 & 2017 & Mean \\
\hline \multirow{11}{*}{ Eastern } & Beijing & 2.981 & 2.681 & 3.155 & 3.232 & 3.554 & 3.332 & 3.563 & 3.665 & 3.621 & 3.684 & 3.732 & 3.751 & 3.766 & 3.440 \\
\hline & Tianjin & 0.764 & 0.773 & 0.816 & 0.832 & 0.846 & 0.847 & 0.859 & 0.823 & 1.014 & 1.117 & 1.231 & 1.134 & 1.513 & 0.967 \\
\hline & Hebei & 0.312 & 0.339 & 0.349 & 0.403 & 0.456 & 0.412 & 0.559 & 0.531 & 0.544 & 0.573 & 0.566 & 0.574 & 0.613 & 0.479 \\
\hline & Liaoning & 0.321 & 0.326 & 0.329 & 0.332 & 0.336 & 0.347 & 0.352 & 0.359 & 0.361 & 0.368 & 0.372 & 0.381 & 0.387 & 0.352 \\
\hline & Shanghai & 2.811 & 2.834 & 2.913 & 2.926 & 2.936 & 2.947 & 2.963 & 2.968 & 2.971 & 2.975 & 2.984 & 2.913 & 2.942 & 2.929 \\
\hline & Jiangsu & 0.811 & 0.812 & 0.815 & 0.824 & 0.845 & 0.815 & 0.817 & 0.835 & 0.839 & 0.857 & 0.869 & 0.899 & 0.932 & 0.844 \\
\hline & Zhejiang & 0.831 & 0.833 & 0.834 & 0.837 & 0.839 & 0.821 & 0.827 & 0.836 & 0.841 & 0.848 & 0.865 & 0.874 & 0.879 & 0.843 \\
\hline & Fujian & 0.719 & 0.734 & 0.736 & 0.735 & 0.756 & 0.734 & 0.745 & 0.749 & 0.753 & 0.757 & 0.756 & 0.758 & 0.759 & 0.745 \\
\hline & Shandong & 0.523 & 0.527 & 0.529 & 0.533 & 0.536 & 0.541 & 0.514 & 0.519 & 0.536 & 0.539 & 0.542 & 0.546 & 0.545 & 0.533 \\
\hline & Guangdong & 0.914 & 0.931 & 0.933 & 0.936 & 0.938 & 0.931 & 0.932 & 0.937 & 0.947 & 0.951 & 0.952 & 0.956 & 0.963 & 0.940 \\
\hline & Hainan & 0.814 & 0.826 & 0.842 & 0.845 & 0.851 & 0.855 & 0.859 & 0.861 & 0.867 & 0.864 & 0.873 & 0.876 & 0.881 & 0.855 \\
\hline \multirow{8}{*}{ Central } & Shanxi & 0.441 & 0.433 & 0.432 & 0.446 & 0.449 & 0.455 & 0.457 & 0.469 & 0.471 & 0.479 & 0.488 & 0.489 & 0.498 & 0.462 \\
\hline & Jilin & 0.532 & 0.541 & 0.544 & 0.546 & 0.557 & 0.539 & 0.563 & 0.564 & 0.568 & 0.569 & 0.571 & 0.578 & 0.579 & 0.558 \\
\hline & $\begin{array}{c}\text { Hei- } \\
\text { longjiang }\end{array}$ & 0.621 & 0.629 & 0.634 & 0.636 & 0.637 & 0.624 & 0.635 & 0.639 & 0.646 & 0.649 & 0.654 & 0.657 & 0.665 & 0.640 \\
\hline & Anhui & 0.731 & 0.735 & 0.739 & 0.738 & 0.732 & 0.743 & 0.752 & 0.766 & 0.771 & 0.738 & 0.739 & 0.743 & 0.758 & 0.745 \\
\hline & Jiangxi & 0.811 & 0.813 & 0.832 & 0.835 & 0.839 & 0.831 & 0.839 & 0.844 & 0.846 & 0.848 & 0.863 & 0.865 & 0.868 & 0.841 \\
\hline & Henan & 0.543 & 0.545 & 0.549 & 0.551 & 0.566 & 0.583 & 0.614 & 0.618 & 0.622 & 0.626 & 0.631 & 0.639 & 0.642 & 0.595 \\
\hline & Hubei & 0.513 & 0.521 & 0.525 & 0.529 & 0.539 & 0.541 & 0.545 & 0.547 & 0.555 & 0.558 & 0.565 & 0.577 & 0.579 & 0.546 \\
\hline & Hainan & 0.789 & 0.786 & 0.702 & 0.712 & 0.728 & 0.721 & 0.726 & 0.736 & 0.736 & 0.745 & 0.757 & 0.763 & 0.769 & 0.744 \\
\hline \multirow{11}{*}{ Western } & Neimenggu & 0.621 & 0.604 & 0.645 & 0.647 & 0.648 & 0.651 & 0.653 & 0.659 & 0.611 & 0.613 & 0.627 & 0.636 & 0.647 & 0.636 \\
\hline & Guangxi & 0.677 & 0.675 & 0.673 & 0.671 & 0.677 & 0.675 & 0.671 & 0.679 & 0.684 & 0.689 & 0.699 & 0.713 & 0.722 & 0.685 \\
\hline & Chongqing & 0.545 & 0.546 & 0.548 & 0.549 & 0.554 & 0.557 & 0.582 & 0.588 & 0.589 & 0.598 & 0.599 & 0.608 & 0.614 & 0.575 \\
\hline & Sichuan & 0.563 & 0.565 & 0.569 & 0.571 & 0.578 & 0.588 & 0.589 & 0.593 & 0.596 & 0.603 & 0.617 & 0.621 & 0.633 & 0.591 \\
\hline & Guizhou & 0.348 & 0.346 & 0.342 & 0.342 & 0.339 & 0.335 & 0.345 & 0.345 & 0.349 & 0.353 & 0.356 & 0.358 & 0.362 & 0.348 \\
\hline & Yunnan & 0.514 & 0.512 & 0.523 & 0.512 & 0.513 & 0.514 & 0.499 & 0.516 & 0.517 & 0.522 & 0.535 & 0.539 & 0.543 & 0.520 \\
\hline & Shaanxi & 0.533 & 0.539 & 0.537 & 0.534 & 0.531 & 0.539 & 0.544 & 0.546 & 0.551 & 0.555 & 0.559 & 0.663 & 0.669 & 0.368 \\
\hline & Gansu & 0.221 & 0.216 & 0.319 & 0.311 & 0.309 & 0.386 & 0.417 & 0.422 & 0.426 & 0.433 & 0.436 & 0.441 & 0.445 & 0.387 \\
\hline & Qinghai & 0.381 & 0.382 & 0.384 & 0.386 & 0.379 & 0.374 & 0.381 & 0.382 & 0.391 & 0.393 & 0.396 & 0.397 & 0.404 & 0.387 \\
\hline & Ningxia & 0.277 & 0.276 & 0.279 & 0.281 & 0.285 & 0.288 & 0.289 & 0.291 & 0.295 & 0.297 & 0.301 & 0.304 & 0.311 & 0.290 \\
\hline & Xinjiang & 0.378 & 0.376 & 0.377 & 0.379 & 0.381 & 0.382 & 0.386 & 0.391 & 0.396 & 0.404 & 0.419 & 0.434 & 0.438 & 0.395 \\
\hline \multicolumn{2}{|c|}{ National Average } & 0.728 & 0.722 & 0.747 & 0.754 & 0.771 & 0.764 & 0.783 & 0.789 & 0.797 & 0.807 & 0.818 & 0.823 & 0.844 & 0.780 \\
\hline
\end{tabular}


solid waste in the main business cost and sales output value of large and medium-sized industrial enterprises in the region [23]. Data of pollution control costs in various regions were collected from China's environmental statistics yearbook, and data of main business costs and sales output value of large and medium-sized industrial enterprises were collected from the website of the state general administration of statistics.

On the basis of setting explained variables and core explained variables, the control variables should also be clarified. Based on the existing research results and the actual situation, the following indicators are selected as the control variables:

1) Per capita GDP, that is, per capita GDP of each province. A lot of data show that the relationship between economic development and the environment presents a KEC curve, so it is expected to be an inverted U-shaped relationship.

2) Industrial structure (PC). The proportion of the secondary industry is expressed as the proportion of the whole industry. Due to the extremely strong pollution of the secondary industry often bringing an inhibitive effect on the green economy, the influence coefficient is expected to be negative.

3) Urbanization (URB) is the proportion of the resident population in each province and city in the total population of the region. This index reflects the degree and process of population convergence in cities. The development of urbanization expands the population size in the region and causes serious pollution problems. Therefore, this study is set as a negative value.

4) Fixed assets investment $(\mathrm{K})$ is the proportion of the total fixed asset investment in the GDP of each province. At present, China is faced with the problem of excess investment in fixed assets, so this paper is set as a negative value.

5) Energy consumption (CS) is the structure mentioned in the process of estimating green innovation efficiency in carbon dioxide emissions, for extra output, considering the pollutant emissions and energy consumption of the relationship between the very closely, therefore, the study on coal consumption in the proportion of the total energy consumption reflects the energy consumption structure, at the same time set to a negative value [24].

\section{SYS - GMM Method}

In the process of the construction of the dynamic panel data analysis model will be explained variable lag item introduced among them, based on avoid endogeneity problem, the purpose of this article through the SYS-GMM method dynamic on provincial panel data regression analysis, through the AR (1), AR (2) and Sargan test to judge the validity of the instrumental variable, degree of recognition. In addition, this study divided 30 samples into the eastern, central and western regions according to provincial and municipal regional standards, and investigated the influence relationship between environmental regulation and green economic efficiency in different regions. Existing studies show that the influence relationship between the two is uncertain and presents nonlinear characteristics. Therefore, the author introduces the quadratic term of environmental regulation into the analysis model. Since the green economic efficiency of enterprises is in the process of gradual accumulation, the lag term of green economic efficiency is introduced into the model.

$$
\begin{gathered}
\ln \mathrm{GF}_{\mathrm{it}}=\beta 0+\beta_{1} \ln \mathrm{Gf}_{\mathrm{it}-1}+\beta_{2} \ln \mathrm{ER}_{\mathrm{it}}+ \\
\beta_{3}(\ln \mathrm{ER})^{2}+\beta_{4} \ln \mathrm{GDP}_{\mathrm{it}}+\beta 5(\ln \mathrm{GDP})^{2}{ }_{\mathrm{it}}+ \\
\beta_{6} \operatorname{lnPC}_{\mathrm{it}}+\beta_{7} \ln \mathrm{URB}_{\mathrm{it}}+\beta_{8} \ln _{\mathrm{it}}+\beta_{9} \ln _{\mathrm{Cit}}+v_{\mathrm{it}}
\end{gathered}
$$

\section{Results and Discussion}

In this paper, the GMM model of the system is used to substitute the data into the estimated results, as shown in Table 3.

(1) Environmental regulation

From the perspective of national samples, we found that the influence coefficient is significantly positive by measuring the lag term of explained variable lnGF, which means that the efficiency of a green economy is in the process of continuous accumulation, and the setting of a dynamic model can be verified as reasonable. By measuring the core variable ln ER quadratic term found influence coefficient is significantly positive, which means that the influence of the relationship between environmental regulation and green economic efficiency comparison $\mathrm{U}$, when environmental regulation efforts remain at a tipping point, it has an inhibitory effect on the efficiency of the green economy, but if the strength lies beyond the tipping point, its role is to promote. In a sense, the relationship between them is not absolutely positive or negative, but complex.

From the point of the sample points of three regions, by estimating the core variables $\operatorname{lnER}$ come to a conclusion: lnER an item and the second item in the eastern region of the coefficient value is significantly positive, $\operatorname{lnER}$ an item in the Midwest region of the coefficient value is significantly negative, which means that the Midwest regional environmental regulation has an inhibitory effect between the green economic efficiency. However, the influence effect of the two factors in the eastern region is accelerative, because the results of estimation (LnER) $)^{2}$ are significantly positive, which can verify that the results of empirical analysis in the eastern region and the whole country are the same, and there is a significant U-shaped relationship between them. Based on regional regression analysis, it is concluded that the environmental regulation adopted in the process of optimizing and adjusting the supplyside structure is conducive to improving the green economic efficiency of the eastern region, but has an inhibitory effect on the green economic efficiency of the central and western regions. On the one hand, different 
Table 3. Regression results.

\begin{tabular}{|c|c|c|c|c|}
\hline & National & Eastern & Central & Western \\
\hline \multirow{2}{*}{$\alpha$} & $0.333^{* *}$ & \multirow{2}{*}{ NA } & $1.321^{*}$ & $1.1725^{*}$ \\
\hline & $(0.0000)$ & & $(0.0001)$ & $(0.0001)$ \\
\hline \multirow{2}{*}{$\operatorname{lnGF}_{\mathrm{it}-1}$} & $0.8766^{* * *}$ & $0.8432 * * *$ & $0.8332 * * *$ & $0.8654 * * *$ \\
\hline & $(0.0000)$ & $(0.0000)$ & $(0.00003)$ & $(0.0001)$ \\
\hline \multirow{2}{*}{ LnER } & $-0.221 * * *$ & $0.326^{* * *}$ & $-0.231 * * *$ & $-0.091 * * *$ \\
\hline & $(0.0001)$ & $(0.0011)$ & $(0.0010)$ & $(0.0013)$ \\
\hline \multirow{2}{*}{$(\mathrm{LnER})^{2}$} & $0.013^{* *}$ & $0.0312 *$ & $0.0364 * *$ & $0.0251 * * *$ \\
\hline & $(0.0050)$ & $(0.0712)$ & $(0.0522)$ & $(0.0001)$ \\
\hline \multirow{2}{*}{$G D P$} & $0.133 * * *$ & $0.1211^{*}$ & $-0.1609 *$ & $-0.2725 * * *$ \\
\hline & $(0.0001)$ & $(0.0742)$ & $(0.0808)$ & $(0.0000)$ \\
\hline \multirow{2}{*}{$(\operatorname{LnGDP})^{2}$} & $0.002 * * *$ & $0.011 * * *$ & $0.021 * * *$ & $0.035 * * *$ \\
\hline & $(0.0001)$ & $(0.000)$ & $(0.000)$ & $(0.000)$ \\
\hline \multirow{2}{*}{$\mathrm{PC}$} & $-0.012 * *$ & $-0.0235^{*}$ & $-0.1304 * *$ & $-0.1732 * *$ \\
\hline & 0.0511 & $(0.0833)$ & $(0.0321)$ & $(0.0416)$ \\
\hline \multirow{2}{*}{ URB } & $-0.112 * * *$ & $-0.0106^{*}$ & -0.0015 & -0.0014 \\
\hline & 0.0002 & $(0.0621)$ & $(0.3713)$ & $(0.2815)$ \\
\hline \multirow{2}{*}{$\mathrm{K}$} & $-0.034 * * *$ & -0.106 & $-0.0268 * *$ & $-0.382 * * *$ \\
\hline & 0.0000 & 0.2501 & 0.0401 & 0.0023 \\
\hline \multirow{2}{*}{$\mathrm{CS}$} & $-0.342 * * *$ & $-0.012 * * *$ & $-0.212 * * *$ & $-0.368 * * *$ \\
\hline & $(0.0001)$ & $(0.0000)$ & $(0.0000)$ & $(0.0001)$ \\
\hline
\end{tabular}

$*, * *$, and $* * *$ are significant under the conditions of $1 \%, 5 \%$, and $10 \%$ respectively.

regions have great differences in regional structure, level of economic development and level of openness. On the other hand, it may be related to the higher degree of economic development, the more perfect market mechanism and the degree of understanding and grasping policies. Therefore, environmental regulations in economically developed areas have more significant effects on improving the efficiency of the green economy.

\section{(2) Analysis of control variables}

With a positive impact on national GDP, overall economic growth promoted the increase of national income, creating more funds that can be used in environmental governance, which is helpful for improving the environment. The impact on the eastern areas is positive while the influence on the Midwest is negative, illustrating how the Midwest's growth depends on the excessive use of energy, exceeding environmental capacity and reducing the efficiency of the green economy. At the same time, its square term is positive, which verifies the inverted U-shaped relationship of GDP influence.

From the perspective of industrial structure, the impact on the efficiency of the green economy is negative, indicating that the higher the proportion of secondary industry, the more detrimental it is to the improvement of the efficiency of the green economy. However, the impact on the eastern region is obviously smaller than that of the central and western regions, indicating that the eastern region has a stronger ability to deal with pollution.

From the point of urbanization, the urbanization rate impact on the efficiency of the national green economy is negative, but not in the Midwest by significance test, namely green economic efficiency for the Midwest region of urbanization impact is not obvious, the main reason is the low level of urbanization in the Midwest, without obvious influence on the regional green economic efficiency, but further urbanization can lead to a green economic efficiency decline. In the eastern region, urbanization has a significant negative impact on the efficiency of the green economy. The level of urbanization in the eastern region is in the stage of rapid progress. The improvement of urbanization is accompanied by the excessive development of resources and energy consumption, which leads to the decline of the efficiency of the green economy.

From the perspective of energy consumption structure, energy consumption structure is negatively correlated with green economic efficiency in the 
whole country and the three regions, indicating that the higher the proportion of coal consumption in energy consumption, the greater the impact on the environment.

Fixed assets are negatively correlated with green economic efficiency in the whole country and the central and western regions, indicating that excessive increases of fixed assets increase energy consumption and have a negative impact on green economic efficiency, while this effect is negative but not significant in the east.

\section{Conclusions}

Our paper uses the super-efficient DEA method to measure the efficiency of China's green economy. On this basis, the SYS-GMM model is built to verify the impact of environmental regulation on the efficiency of China's regional green economy, and our conclusions are as follows:

(1) From the results of green economic efficiency calculations, the green economic efficiency of Beijing, Shanghai, Tianjin and Guangdong is at a higher level, both higher than 0.9 . The green economic efficiency is below 0.5 in Guizhou, Gansu, Hebei, Liaoning, Shanxi, and Shaanxi. In 10 regions, including Ningxia, Qinghai, Xinjiang and Qinghai, six of them are in the west, and the region with green economic efficiency between 0.5 and 0.9 is the majority. From the national sample, the impact relationship shows an inverted "U" type between environmental regulation and green economic efficiency. When the environmental regulation intensity is kept within a certain critical point, its effect on the efficiency of the green economy is restrained, but if this strength exceeds this critical point, its impact is promoted. In a sense, the relationship between the two is not absolutely positive or negative, but complex.

(2) From the perspective of the three regions, environmental regulation has an inhibitory effect on green economic efficiency of the central and western regions; but the impact on the eastern region is promoted, and there is a significant " $U$ " shape relationship in the eastern region. It can be found that the environmental regulation adopted in the process of optimizing and adjusting the supplyside structure helps to improve the efficiency of the green economy in the eastern region, but it has an inhibitory effect on green economic efficiency in the central and western regions. The reason is that, on the one hand, there are big differences in regional structure, economic development level and openness level in different regions; on the other hand, it may be related to the degree of economic development, market mechanisms might be relatively perfect, understanding and grasping policies. The effectiveness of environmental regulation in developed regions in improving the efficiency of the green economy is even more pronounced.
The research in this paper has important theoretical reference significance for correctly understanding the efficiency of the green economy and formulating regional environmental regulations with appropriate intensity, so as to comprehensively improve the efficiency of the green economy and promote green economic growth [25].

\section{Acknowledgements}

This work was supported by School-level Scientific Research Fund Project of Nanjing Institute of Technology: Evaluation and Improvement of Ecological Welfare Performance in China from the Perspective of High Quality Development (Project Number: CKJA201905).

\section{Conflict of Interest}

The authors declare no conflict of interest.

\section{References}

1. HUANG S., CHEN D. HAS ENVIRONMENTAL REGULATION RESTRAINED SMOG POLLUTION: EVIDENCE FROM CHINA. Singapore Economic Review, (1), 1, 2017.

2. ZHAO Y., HONG Y., HUANG Y. J. Relationship between $R \& D$ investment and business performance from the perspective of environmental regulation: Takeing the heavy-polluting industries from 2011 to 2016 as an example. Ecological Economy, (3), 213, 2017.

3. CHEN J.J., CHAMBERS D. Sustainability and the impact of Chinese policy initiatives upon construction[J]. Construction Management \& Economics, 17 (5), 679, 1999.

4. MACKENZIE I.A. Rent creation and rent seeking in environmental policy. Public Choice, 171 (1-2), 1, 2017.

5. WELFENS P.J.J., PERRET J.K., ERDEM D. Global economic sustainability indicator: analysis and policy options for the Copenhagen process. International Economics \& Economic Policy, 7 (2-3), 153, 2010.

6. CARRARO C., BUCHNER B.K. Economic and Environmental Effectiveness of a Technology-based Protocol. Social Science Electronic Publishing, 4 (3), 22, 2004.

7. KRUTILLA K. Environmental regulation in an open economy. Journal of Environmental Economics \& Management, 20 (2), 127, 1991.

8. HAHN R.W. The political economy of environmental regulation: Towards a unifying framework. Public Choice, 65 (1), 21, 1990.

9. ZHANG H., ZHU Z., FAN Y. The impact of environmental regulation on the coordinated development of environment and economy in China. Natural Hazards, 91 (2), 473, 2018.

10. WANG Z., ZHANG B., ZENG $\mathrm{H}$. The effect of environmental regulation on external trade: empirical evidences from Chinese economy[J]. Journal of Cleaner Production, 114 (2), 55, 2016. 
11. HUANG D.H., LIU Z.B. Environmental regulation and enterprise independent innovation -construction of enterprise competitive advantage based on porter hypothesis. China industrial economy, (3), 100, 2006.

12. ZHANG C., LIU H., BRESSERS H.T.A., BUCHANAN K.S. Productivity growth and environmental regulationaccounting for undesirable outputs: Analysis of China's thirty provincial regions using the Malmquist - Luenberger index. Ecological Economics, 70 (12), 2369, 2011.

13. HE A.P., AN M.T. Local government competition, environmental regulation and green development efficiency . China population, resources and environment, (3), 21, 2019.

14. GOLLOP F.M., ROBERTS M. Environmental Regulations and Productivity Growth: The Case of fossil-fueled Electric Power Generation. Journal of Political Economy, 91 (4), 654, 1983.

15. KE W.L., SHA J.H., YAN J.J. Characteristics of environmental Kuznetz curve and analysis of its influencing factors in Shanxi Province. China population, resources and environment, 136 (s2), 389, 2011.

16. WANG G.Y.,WANG D. Porter hypothesis, environmental regulation and enterprise technology innovation - a comparative analysis of central and eastern China . China soft science, (1), 100, 2011.

17. LIU M.Y. Spatial heterogeneity effect of environmental regulation and green innovation efficiency - based on data of industrial enterprises in the Yangtze river economic belt. Journal of finance and accounting (part ii), 844 (12), 144, 2018.
18. JIN Y.G., CHANG R. Environmental regulation and industrial total factor productivity - an empirical study based on dynamic panel data of 280 prefecture-based cities. Economic issues, (11), 18, 2016.

19. YANG L., WANG K.L. Regional differences of environmental efficiency of China's energy utilization and environmental regulation cost based on provincial panel data and DEA method. Mathematical \& Computer Modelling, 58 (5-6), 1074, 2013.

20. WANG Z., FENG C. The impact and economic cost of environmental regulation on energy utilization in China. Applied Economics, 46 (27), 3362, 2014.

21. LIAN T., MA T., JIE C., YOU W. The effects of environmental regulation on the industrial location of China's manufacturing. Natural Hazards, 80 (2), 1381, 2016.

22. BEI J., GANG L. Green economic growth from a developmental perspective [J]. China Finance \& Economic Review, 1 (1), 1, 2013.

23. AYERBE C.G., GÓRRIZ C.G. The Effects of Environmental Regulations on the Productivity of Large Companies: An Empirical Analysis of the Spanish Case. Journal of Management \& Governance, 5 (2), 129, 2001.

24. WANG Q., PENG Z., ZHOU D. Efficiency measurement with carbon dioxide emissions: The case of China. Applied Energy, 90 (1), 161, 2012.

25. YU Z. State power and environmental initiatives in China: Analyzing China's green building program through an ecological modernization perspective. Geoforum, 61 (5), $1,2015$. 